\title{
Crime scene investigators
}

\section{Forensic science is swamped with applicants, but a pure science degree will put you ahead of the crowd.}

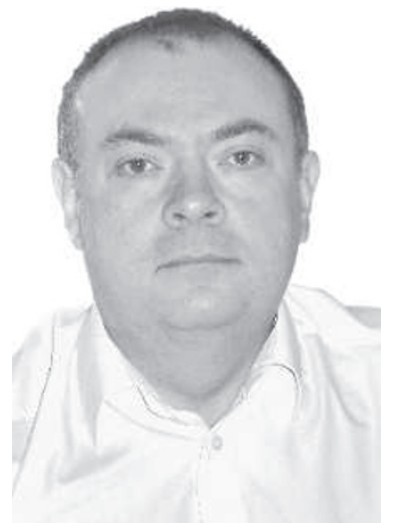

Richard Smith
For many people, forensics makes science sexy. A combination of intrigue, curiosity and élitism has captured the imagination of millions who regularly tune into programmes such as CSI: Crime Scene Investigation, Waking the Dead and Silent Witness. But forensics is not only popular material for television. Interest in the subject as a career has grown, reflected in the number of applicants for jobs in the sector.

In the decade or so that this kind of show has been popular, LGC Forensics, the largest independent forensic service in the United Kingdom, has seen a steep increase in the number of job applications. Now the company, which offers consultative and analytical forensics services to UK police forces and other agencies, routinely receives several thousand applications each year for as few as 50 vacancies. The growth seems to suggest a direct correlation with TV exposure, although the link is hard to prove. Before the explosion of forensic science in the media, there was a steady trickle of applications, usually in the hundreds.

As with most forms of recruitment, it is important to attract interest. But with thousands continuing to apply it can be a logistical nightmare trying to put together a shortlist for interview.

The university system in Britain also views forensic science as an opportunity to attract students. Hundreds of courses include 'forensics' in

"A proposed
master's
degree will
cover key
areas, such as
lab work and
the legal
process."
their titles - it's a way of selling science. As former chairman of a governmentsponsored national enquiry into UK higher education and forensic science, I found that the subject attracted students who otherwise might not have pursued a science degree. This, one could argue, is a success story in its own right.

But some students and prospective job applicants mistakenly feel that pursuing a forensic-science degree will provide a major advantage over pure science qualifications. Angela Gallop, director of LGC Forensics, always encourages students to take a first degree in pure science, arguing that a grounding in science is the best preparation for a career in forensics or any analytical science area.

LGC Forensics' experience suggests that many (although not all) of the applicants who apply

\section{"It can take many years to gain the experience and skills needed to work at senior level."}

for jobs actually lack the 'pure science' skills and knowledge needed. Despite the increasingly large applicant pool, in some cases there was a need to provide several weeks of remedial training in areas such as analytical chemistry.

Much of LGC Forensics' recruitment takes place at entry/ junior level - developing skills in areas such as forensic biology, chemistry, toxicology and ecology. It can take many years of personal and professional development to gain the experience and skills needed to work at senior levels, which usually involves presenting forensic evidence in court and taking on case management. LGC Forensics has clearly defined and flexible development pathways, such as training in areas of forensic biology, followed by additional modules that will let employees build on their knowledge and skills.

Looking to foster innovative approaches as the demand for forensic services continues to grow, LGC approached the University of Oxford to explore a new idea - the development of an MSc in applied analytical science. This would cover key areas of forensic and analytical practice, including investigations at crime scenes, forensic science in the laboratory, and legal process in courts of law. The proposed degree builds on existing master's degrees in forensic science, for example at the University of Strathclyde in Scotland and King's College London, to accommodate the skills needed within the company. It is also likely to benefit other businesses and employers in the area of forensic-analytical science.

LGC Forensics has developed an outline programme composed of science subjects, the legal process and investigation. It has also made a commitment to provide expertise on curriculum development and teaching, including work placements. This approach is aligned with the UK government's call for industryacademic collaborations that offer greater cohesion and mutual benefit.

Our Oxford collaborators believe that this programme is an opportunity to provide a world-class course in vital areas of analytical science. For LGC, it will provide a valuable development tool for people in the company, while enabling other students to get a firmer grasp of the realities of forensics and analytical science. We hope to start accepting students for the 2009 academic year.

Through programmes such as these, we can develop the analytical skills of the future and ensure that forensics continues to be populated by specialists who possess both an intense curiosity and a knack for science.

Richard Smith is project director for the LGC Forensics/Oxford Programme and associate director of Winchester Consulting in Hampshire, UK. www.lgc.co.uk

www.wincon.co.uk 